\title{
The role of standing in the psychology of procedural justice: towards theoretical integration
}

\author{
Jan-Willem van Prooijen \\ Free University Amsterdam, The Netherlands \\ Kees van den Bos \\ Utrecht University, The Netherlands \\ Henk A. M. Wilke \\ Leiden University, The Netherlands
}

\begin{abstract}
In the current chapter, the authors explore the relation between social standing and procedural justice. Standing is an important construct in procedural justice theories and tends to be broadly defined as the position that people have in social groups. It is argued that the standing construct suffers from conceptual ambiguity: In procedural justice literature two distinct interpretations of standing can be distinguished, one defining standing as intragroup status and one defining standing as the extent to which people are included in social groups. Furthermore, it is argued that research findings on the relation between standing and procedural justice are not conclusive. The authors review recent empirical findings that address these concerns, and conceptually integrate these findings. In closing, the authors outline avenues for future research that the procedural justice field may want to take, and discuss implications of the work reviewed here.
\end{abstract}

Social justice is essential to understand human behaviour. That is, people are affected by the extent to which social situations are perceived as fair, usually react positively when they are treated fairly, and show appreciation when they think that justice is done (for a review see, e.g., Lind \& Tyler, 1988). Furthermore, unfair treatment may lead to aversive reactions such as feelings of anger, fear, and disgust (e.g., Folger \& Cropanzano, 1998). It has even been argued that social justice constitutes one of the most fundamental

Address correspondence to: Jan-Willem van Prooijen, Department of Social Psychology, Free University Amsterdam, Van der Boechorststraat 1, 1081 BT Amsterdam, the Netherlands. Email: jw.van.prooijen@psy.vu.nl

We would like to thank Wolfgang Stroebe and all the anonymous reviewers for their constructive comments on previous drafts of this chapter.

(C) 2004 European Association of Experimental Social Psychology

http://www.tandf.co.uk/journals/pp/10463283.html

DOI: $10.1080 / 10463280340000108$ 
norms and values in human society (e.g., Folger, 1984). One justice concern that people have is related to the distribution of resources: People want to receive fair outcomes (e.g., salaries). People's perceptions of outcome fairness are studied in the scientific domain that is usually called the psychology of distributive justice (e.g., Adams, 1965). A related but different justice concern that people have refers to decision-making processes: People want the procedures that precede decisions to be fair. The perceived fairness of decision making procedures has been referred to as the psychology of procedural justice (e.g., Lind \& Tyler, 1988; Thibaut \& Walker, 1975; Tyler $\&$ Lind, 1992). The distinction between distributive and procedural justice is important, because the classic work of Thibaut and Walker (1975) has demonstrated that people's justice concerns indeed involve questions about both the fairness of outcomes and the fairness of procedures.

Justice is essentially a social phenomenon, because experiences of (in)justice are products of people's interactions with other people in social settings (Lind \& Tyler, 1988). More generally, it has been argued that social relationships are interwoven with people's experiences of social justice (Folger \& Cropanzano, 1998; Lind \& Tyler, 1988; Tyler \& Blader, 2000; Tyler \& Lind, 1992; Van den Bos \& Lind, 2002). An important social factor that has been related to both distributive and procedural justice is a factor referred to as "standing". Procedural justice researchers tend to broadly define standing as the position that people occupy within a group (e.g., Lind \& Tyler, 1988; Tyler, 1989, 1994). In the distributive justice literature, researchers have adopted a more specific definition of standing: Distributive justice researchers have operationalised standing as people's individual status within a group (e.g., Feather, 1994). It has been argued that this operationalisation of standing is related to distributive justice because status differences may affect people's perceptions of entitlement: People's intragroup status determines whether or not people perceive themselves as entitled to certain outcomes, and this affects subsequent distributive justice judgements (Feather, 1994). To illustrate, people may perceive differences in outcomes (e.g., salaries) as fair depending in part on status differences (e.g., full professors vs assistant professors). People's individual status positions within a group can thus affect distributive justice judgements.

Several authors have argued that standing is not only related to the psychology of distributive justice, but is also an important social factor in the procedural justice domain (Cropanzano, Rupp, Mohler, \& Schminke, 2001b; Folger \& Cropanzano, 1998; Lind, 2001; Lind \& Tyler, 1988; Tyler \& Lind, 1992; Van den Bos \& Lind, 2002). Empirical studies have indeed shown that perceptions of social standing are related to procedural justice judgements (e.g., Chen, Brockner, \& Greenberg, 2003; Smith \& Tyler, 1997; Tyler, 1989, 1994; Tyler \& Blader, 2002; Tyler, Degoey, \& Smith, 1996). Although these empirical studies provide some evidence for a relation 
between standing and procedural justice, in the current chapter we argue that there are several ambiguities about this relation that need to be resolved. That is, we argue that (1) unlike distributive justice researchers, procedural justice researchers have not been very specific in their interpretation of standing; as a consequence, various procedural justice researchers have defined social standing in various ways; (2) empirical research data about the relation between standing and procedural justice are not conclusive; and (3) it is as yet unclear how the relationship between standing and procedural justice should be explained. In the following, we provide a brief overview of the procedural justice field, and review theories and empirical studies that have concentrated on the relation between standing and procedural justice. Furthermore, we point out the limitations of current knowledge on the standing construct in procedural justice. After this, we review some of our own recent studies that illuminate the relation between standing and procedural justice. We conclude this chapter by theoretically integrating these propositions and by providing avenues for future research that the procedural justice field may want to take.

\section{STANDING AND PROCEDURAL JUSTICE}

\section{Theoretical background}

An illustration of a procedural justice phenomenon is the finding that people evaluate procedures that allow them an opportunity to voice their opinion in a decision-making process to be more fair than procedures that do not allow them such an opportunity (Folger, 1977; Folger, Rosenfield, Grove, \& Corkran, 1979; cf. Brockner et al., 1998; Greenberg \& Folger, 1983; Lind, Kanfer, \& Earley, 1990; Tyler, 1987; Van den Bos, 1999). Furthermore, it has been shown that voice procedures have the potential to affect a wide range of people's reactions, such as satisfaction ratings and evaluations of relations with authorities. These latter effects of voice constitute examples of the more general finding that perceived procedural fairness affects many human perceptions and behaviours (e.g., Folger et al., 1979; Greenberg \& Folger, 1983; Van den Bos, Bruins, Wilke, \& Dronkert, 1999; Van den Bos, Lind, Vermunt, \& Wilke, 1997a; Van den Bos, Wilke, Lind, \& Vermunt, 1998b). In the current chapter we refer to the effects of procedures on procedural justice judgements and subsequent satisfaction ratings and relational treatment evaluations as procedural fairness effects (Van Prooijen, Van den Bos, \& Wilke, 2002). Procedural fairness effects are robust and generalise across methodologies and samples (Folger et al., 1979; Greenberg \& Folger, 1983; Lind \& Tyler, 1988; Van den Bos, Wilke, \& Lind, 1998a).

Several theories have been developed to explain procedural fairness effects (for overviews, see Brockner \& Wiesenfeld, 1996; Cropanzano, 
Byrne, Bobocel, \& Rupp, 2001a; Folger \& Cropanzano, 1998; Lind \& Tyler, 1988; Tyler \& Blader, 2000; Tyler \& Lind, 1992; Van den Bos \& Lind, 2002). Of these theories, the relational model of authority has explicitly stated that standing has a pivotal role in explaining procedural fairness effects (Lind \& Tyler, 1988; Tyler \& Lind, 1992). In our discussion of the standing construct in procedural justice we therefore concentrate on the relational model. This model emphasises the importance of group membership in the psychology of procedural justice. Inspired by social identity theory (Tajfel \& Turner, 1979), the relational model assumes that people have a basic need to be a member of valued social groups (see also Baumeister \& Leary, 1995; Brewer, 1991; Tajfel \& Turner,1979; Turner, Hogg, Oakes, Reicher, \& Wetherell, 1987). Furthermore, people want to know whether they are respected and valued as members of their social groups (Tyler et al., 1996). As a result, people search for information about the extent to which they are respected by their fellow group members. People can find such information, the relational model argues, by looking at the way in which they are treated by group authorities, because authorities are generally perceived to be representative of the entire group (Tyler \& Lind, 1992). If group authorities treat people with dignity, people infer that they are respected members within their group and that they can be proud to be a member of their group. If group authorities treat people rudely, people conclude that they are not respected members within the group and that they should not have pride in their group membership (Tyler et al., 1996).

An example of an empirical study illuminating the relation between group membership and procedural justice has been reported by Smith, Tyler, Huo, Ortiz, and Lind (1998). These authors manipulated group membership of the experimenter (a relevant authority in procedural justice experiments) by informing participants that the experimenter's university affiliation was the same as (ingroup condition) or different from (outgroup condition) the participant's own university affiliation. Furthermore, participants conducted a skill test, and this introduced the following procedural justice manipulation: The experimenter either graded the test accurately and allowed participants the opportunity to express their reactions to the test (high treatment quality condition) or the experimenter did not grade the test accurately and did not allow participants the opportunity to express their reactions to the test (low treatment quality condition). Results showed that participants' relational treatment evaluations were affected more strongly by the treatment quality manipulation when the experimenter was an ingroup member than when the experimenter was an outgroup member. These results are in correspondence with predictions from the relational model: People attach more value to the way they are treated by ingroup authorities than by outgroup authorities, because ingroup authorities are more informative about crucial relational 
matters, such as the extent to which people are regarded as respected members within their group (see also Ståhl, Van Prooijen, \& Vermunt, in press).

To understand findings such as those reported in Smith et al. (1998) more thoroughly, the relational model has stated (among other things) that how people are treated by group authorities is informative about their intragroup standing - that is, it reveals important information about the position that people have in the group (Tyler, 1989, 1994). Positive treatment communicates that the authority regards people as accepted as fully-fledged members of the group (Lind, 2001; Lind \& Tyler, 1988) and as having high status within the group (Tyler, 1989, 1994). Negative treatment, however, communicates that the authority regards people as marginal members of the group and as having low status within the group. The relational model further argues that information about standing subsequently shapes people's reactions to later experienced fair and unfair procedures (Tyler, 1994). The relational model thereby assumes the following causal order between standing and procedural justice: Information about people's position in social groups influences procedural fairness effects.

There is some empirical support for the above-described relationship between standing and procedural justice phenomena, as survey studies have demonstrated significant correlations between standing and procedural justice judgements (e.g., Tyler, 1989, 1994; Tyler \& Blader, 2002; Tyler et al., 1996; see also Chen et al., 2003; Smith \& Tyler, 1997). An example of such a study is Tyler (1989), who conducted a telephone survey among citizens in Chicago to assess their experiences with legal authorities. In this study, Tyler operationalised people's perceptions of standing by asking participants how polite authorities had been to them and to what extent authorities had respected their rights. The results of this study showed that Tyler's operationalisation of standing was indeed correlated with procedural justice judgements. Based on this evidence, it was concluded that standing is related to procedural justice judgements.

\section{Limitations}

The above considerations suggest that scientists now understand a good deal of the relation between standing and procedural justice. However, we argue here that several theoretical and empirical obstacles have not yet been resolved by the relational model and empirical research that followed from the model. First, in the procedural justice field there is considerable conceptual ambiguity about the standing construct. That is, various justice researchers have defined standing in various ways (Cropanzano et al., 2001b; Lind, 2001; Tyler \& Blader, 2002). Some researchers have defined standing in terms of intragroup status (Tyler, 1989, 1994; Tyler et al., 1996; 
see also Cropanzano et al., 2001a). Notably, Tyler (1989, 1994) equated standing with status recognition and noted that procedural justice is related to the extent to which people conclude that they have high or low intragroup status. However, other researchers have objected to this status definition and have instead stated that standing should be defined as messages of inclusion (Lind, 2001; Lind \& Tyler, 1988). An illustration of this latter position can be found in a critique by Lind (2001, p. 224) on a paper in which the status definition was adopted (i.e., Cropanzano et al., 2001a):

In both the original presentation of the theory (Lind \& Tyler, 1988) and in the later (Tyler \& Lind, 1992) application of the theory to justice and obedience to authority, we said that people value procedures that give them "standing," which we defined as messages of inclusion, regardless of status. The difference is subtle, but important. In a fair organisation, according to our original formulation, a member at any level can find procedures and processes that affirm his or her membership, inclusion, and importance to the organisation. There may be status differences, but the key element of fairness in group-value theory is inclusion, not rank. The authors are certainly to be forgiven for confounding these ideas, since Tyler and I have spoken with different voices about this. I have tended to hold fast to the standing construction, but Tyler often has written of the construct as though standing and status were the same thing or as though status, not standing, was the key element".

Thus, there is considerable disagreement about what role standing has in the psychology of procedural justice, which is illustrated by the fact that even the two originators of the relational model (Lind and Tyler) do not agree on its definition. Related to the above quote by Lind (2001), Cropanzano et al. (2003b) have also noted explicitly that the definitions of standing that were adopted by procedural justice researchers can be broadly categorised into two classes, one referring to intragroup status (e.g., Tyler, 1989, 1994; Tyler et al., 1996; Smith \& Tyler, 1997) and one referring to social inclusion or exclusion (e.g., De Cremer, 2002; Lind, 2001; Lind \& Tyler, 1988).

The distinction of two different operationalisations of standing that were observed by Cropanzano et al. (2003b) and by Lind (2001) corresponds to a recent distinction in an empirical research study between what has been labelled "comparative" and "autonomous" standing (Tyler \& Blader, 2002). According to these authors, comparative intragroup standing corresponds to intragroup status and is based on social comparison of external standards, such as objective performance differences between individuals. To illustrate, high achievers typically infer that they have higher comparative standing in a group than low achievers. Thus, people use external comparison standards to determine their rank in the group. Autonomous standing is based on internal standards such as values and norms, which people use to consider where they stand in terms of the 
standards that define the group. According to Tyler and Blader (2002), people compare their internalised personal values with prototypical group values to determine whether they are included in or excluded from the group. For example, if an individual's personal norms and values correspond to group norms and values, the individual may infer that he or she is included in the group. However, if the individual's normative fit within the group is poor, the individual may conclude that he or she does not really belong to the group and is excluded (cf. Cropanzano et al., 2001b; Lind, 2001). ${ }^{1}$ The Tyler and Blader (2002) study constitutes the first effort to empirically disentangle the different definitions of standing. Given that since the development of the relational models of justice (Lind \& Tyler, 1988) researchers have variously defined standing either as status or as inclusion, it can be concluded here that over the last 15 years, procedural justice researchers have not consistently referred to the same concept when referring to standing.

A second limitation of current knowledge on the relation between standing and procedural justice is that empirical research findings have not been conclusive. More specifically, although the relational model has assumed that perceptions of standing causally affect procedural fairness effects, most of the research data that examined the relation between standing and procedural justice were correlational survey data (e.g., Tyler, 1989, 1994; Tyler \& Blader, 2002; Tyler et al., 1996; Smith \& Tyler, 1997). As a consequence, it is as yet unclear whether correlations between standing and procedural justice constitute real or spurious relations, and it is impossible to draw conclusions about causality.

Related to this, we argue here that empirical studies have not operationalised the standing construct as accurately as possible. For example, in Tyler $(1989,1994)$ standing was operationalised by asking participants whether or not their rights were respected by authorities. Furthermore, in the Tyler and Blader (2002) study, autonomous and comparative standing judgements were measured by assessing participants' perceptions of whether or not they were respected by authorities and whether or not they had pride in their group memberships (see also

\footnotetext{
${ }^{1}$ Although "autonomous" standing depends less on comparison processes than "comparative" standing does, it is noteworthy that the former also depends - at least to some extent - on some comparisons being made by people forming standing and justice judgements (e.g., comparisons between the individual's and the group's norms and values). However, the precise labelling used in the Tyler and Blader (2002) study is not our focus of attention here, but the main issue for the current chapter is the distinction between "standing-as-inclusion" (Lind, 2001; Lind \& Tyler, 1988) and "standing-as-status" (Tyler, 1989, 1994; Tyler et al., 1996; see also Cropanzano et al., 2001a) conceptions of the standing construct, as discussed by Lind (2001) and Cropanzano et al. (2001b).
} 
Smith \& Tyler, 1997; Tyler et al., 1996). Specifically, in the Tyler and Blader (2002) study the authors distinguished between four standing variables - autonomous pride (measured with items such as "I feel proud to be a part of my work group"), autonomous respect (measured with items such as "Would you agree or disagree that your managers value what you contribute at work?"), comparative pride (measured with items such as "I work in one of the best work groups in my organisation"), and comparative respect (measured with items such as "Would you agree or disagree that your managers respect you more than other employees?"). Although it is likely that these operationalisations are related to people's perceptions of their position in the group, it can be argued that at best these operationalisations constitute indirect measurements of the standing construct. For example, it is disputable whether Tyler and Blader's operationalisations of "autonomous pride" and "respect" really are indicative for people's perceptions of whether they are included or excluded.

As a third limitation, it can be noted here that it is unclear how the relation between standing and procedural justice should be explained. More specifically, the relational model has not been very explicit about which psychological processes it is assuming (Ambrose \& Kulik, 2001). More generally, it has been argued that the relational model should be conceived of as a descriptive model, not as a process model (Cropanzano et al., 2001a). Based on the relational model, therefore, relatively little is known about the underlying psychological processes of how standing influences people's experiences of and reactions to procedural fairness.

These considerations lead us to argue here that there are challenging opportunities left to further explore the role of standing in the psychology of procedural justice. We propose some refined hypotheses as to the relation between procedural justice and standing. In the current chapter, we try to do this by reviewing the results of a number of recent studies in which we address some of the mentioned limitations of scientists' understanding of the relation between standing and procedural justice. In the following, we review recent empirical findings on both the status definition of standing (Tyler, 1989, 1994; Tyler \& Blader, 2002) and on the inclusion definition of standing (Lind, 2001; Lind \& Tyler, 1988). Furthermore, the reviewed studies experimentally manipulated status and inclusion to demonstrate causal effects of both standing operationalisations on procedural fairness effects, and have assessed cognitive process measures to investigate exactly how the relation between standing and procedural justice should be explained. Following the studies, we conceptually integrate these findings with existing knowledge and discuss avenues for future research. 


\section{EMPIRICAL FINDINGS}

\section{Status and procedural justice}

To investigate the status definition of standing, we have conducted experiments on both status salience and intragroup status. The status salience studies were intended to provide insights into the psychological process of how status influences reactions to procedures. More specifically, in the status salience studies we investigated whether cognitively activating the general construct status would be sufficient to influence procedural fairness effects. In the experiments on intragroup status we investigated the implications of the status salience findings in a context with real intragroup status differences. We now introduce the studies in more detail.

Status salience. Building on the relational model, we have set up two experiments to explore the effects of status salience on procedural fairness effects (Van Prooijen et al., 2002). In these studies, we posited that people mentally associate social status with the regard and approval that they receive from other people (cf. Tyler et al., 1996). As a consequence, we argued, cognitive accessibility of the status construct (e.g., because of answering questions about status in a survey) leads to an increased concern for the regard and approval that people receive from others. In situations where status is made cognitively accessible, people therefore seek information that informs them about the extent to which they are held in regard by other people. Such information about regard and approval may be found in procedural justice information. It has been argued before that procedural justice is informative about the extent to which people are held in regard by others (Tyler \& Lind, 1992). People should therefore be more attentive to procedural justice information in situations where status is made cognitively accessible than in conditions were status is not made cognitively accessible.

Based on the above line of reasoning, we have investigated the hypothesis that status salience leads to stronger procedural fairness effects (Van Prooijen et al., 2002). The first experiment reported in Van Prooijen et al. (2002) took place behind computers in separate cubicles. Participants were informed that the experimenter could send computer messages to the participants. Additionally, participants learned that a lottery would be held among participants, and that the experimenter would assign a number of lottery tickets to the participant. Following this information, the status salience manipulation was induced. Participants in the status salient condition were asked to answer two open-ended questions concerning their thoughts and emotions about the concept status (cf. Van den Bos, 2001; Van den Bos \& Miedema, 2000): "Please describe briefly the thoughts and emotions that come to mind when you think of the concept status" and "Please describe a situation out of your own life in which status played a 
role". In a control condition, participants responded to two similar questions about something that was not related to the status manipulation: watching TV (cf. Van den Bos, 2001).

Following this status salience manipulation, participants were exposed to the procedure manipulation: Participants experienced either a voice or a novoice procedure (Folger, 1977; Folger et al., 1979; cf. Brockner et al., 1998; Lind et al., 1990). In the voice condition, participants received a computer message from the experimenter stating that they were allowed an opportunity to voice their opinion about the percentage of lottery tickets they thought they should receive. These participants subsequently typed in a percentage. In the no-voice condition, participants were informed that they were not allowed an opportunity to voice their opinion about the percentage of lottery tickets they thought they should receive. These participants did not type in a percentage. We then solicited the dependent measures and manipulation checks. The main dependent measures were relational treatment evaluations: Specifically, we asked on 7-point scales whether participants thought the experimenter respected them, trusted them, and treated them politely. The results of this experiment showed a significant interaction effect that is depicted in Figure 1. These results revealed that, as predicted, procedural fairness effects were stronger in the status salient condition than in the control condition. These findings were in line with the general argument that salience of the status construct amplifies procedural fairness effects compared to situations where status is not salient.

In a second experiment, we tried to obtain evidence for a fundamental assumption of our line of reasoning: Our line of reasoning assumes that status salience leads to an increased cognitive accessibility of fairness concerns. Additionally, we tried to replicate the results of Experiment 1. The second experiment was introduced as two separate studies. In "Study 1" we induced the same status salience manipulation as in Experiment 1. After this, we collected cognitive accessibility data as a manipulation check to ascertain whether status salience really made people's fairness concerns more cognitively accessible. We did this by means of a word-fragment completion task, which was assessed after the status salience manipulation and before the procedure manipulation. Participants were presented with six uncompleted Dutch words (e.g., "... nrecht") that could either be completed as a fairness-related word (e.g., "onrecht", which means unjust) or as a nonfairness related word ("aanrecht", which means kitchen sink; for details, see Van Prooijen et al., 2002). We counted the number of fairness-related words each participant came up with. Word-fragment completion tasks such as these are commonly conceived of as unobtrusive measures of construct accessibility (e.g., Chen, Lee-Chai, \& Bargh, 2001).

Following the word-fragment completion task, participants were informed that "Study 1" had ended and that they would continue with 


\section{- Voice procedure}

$\square$ No-voice procedure

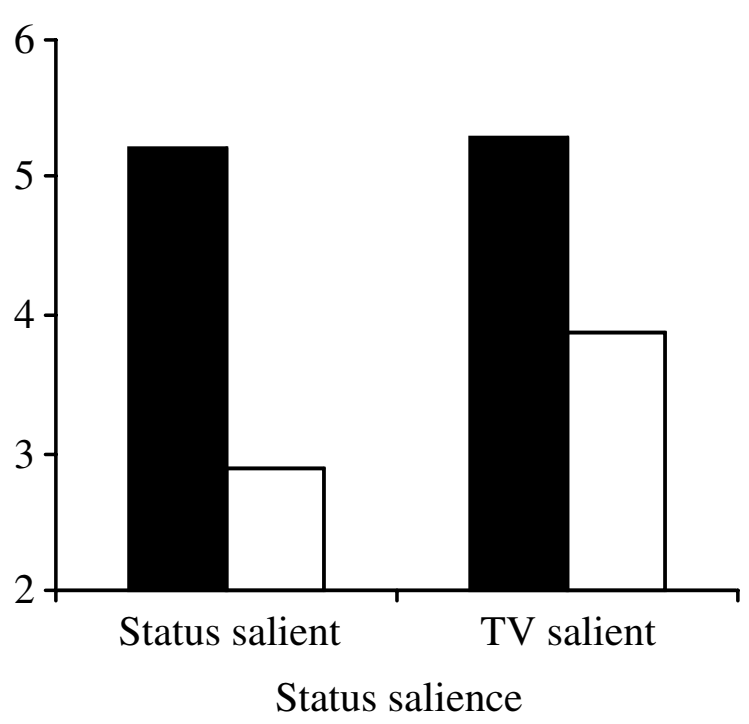

Figure 1. Mean relational treatment evaluations as a function of status salience and procedure. Relational treatment evaluations were measured on 7-point scales with higher means indicating more positive relational treatment evaluations. Adapted from Van Prooijen et al. (2002).

"Study 2". This study was a scenario experiment in which participants imagined themselves to be workers in a factory. Participants were informed that the management would base the magnitude of a one-time only financial bonus on their work performance. Furthermore, participants were told that within their work they had 10 different activities. We then manipulated procedural accuracy by informing participants that the management had taken 10 out of 10/1 out of 10 activities into account to evaluate their work performance. Procedural accuracy is a robust alternative to voice as opposed to no-voice procedures for studing procedural fairness effects (Van den Bos, 2001; Van den Bos \& Miedema, 2000; Van den Bos, Vermunt, \& Wilke, 1997b). Main dependent measures were again relational treatment evaluations.

Manipulation-check findings of Experiment 2 showed that participants in the status salient condition came up with significantly more fairness-related words in the word-fragment completion task than participants in the control condition. These findings show that in situations where status is salient, 
fairness concerns become more cognitively accessible. This suggests that people are more attentive to fairness information if they are focused on status than if they are focused on a nonstatus issue. Furthermore, in correspondence with the findings obtained in Experiment 1 (see Figure 1) we again found stronger procedural fairness effects in the status salient condition than in the control condition. It can therefore be concluded that salience of the construct status amplifies procedural fairness effects. We now describe studies in which we have investigated the implications of these findings in situations with real intragroup status differences.

Intragroup status. In two different experiments we manipulated participants' intragroup status position (Van Prooijen, Van den Bos, \& Wilke, 2003). The aims of these experiments were twofold. First, we wanted to investigate whether the presence of status information would lead to stronger procedural fairness effects when compared with a condition where one's intragroup status was unknown. Stronger procedural fairness effects in conditions where status information was present as opposed to absent would be in correspondence with the status salience findings (Van Prooijen et al., 2002): After all, it stands to reason that emphasising people's intragroup status position makes the concept status salient, which is mentally associated with the regard and approval that people receive from others. As a consequence, people are relatively more attentive to procedural fairness information. As such, this experiment directly tests the relational model's proposition that status information causally shapes procedural fairness effects (Tyler, 1994). Second, we wanted to find out whether procedural fairness effects would be more or less pronounced for specific status positions (i.e., high vs average vs low). This extends the status salience findings of Van Prooijen et al. (2002), because in the status salience experiments we only concentrated on procedural fairness effects following the general concept status instead of procedural fairness effects as a function of status differences.

For the sake of brevity, we only discuss Experiment 2 of Van Prooijen et al. (2003) (Experiment 1 was a scenario experiment that showed similar results on the same dependent and independent variables as Experiment 2). Experiment 2 took placein individual cubicles and behind computers. Participants were placed in an alleged laboratory group of eight persons who were supposed to be seated in eight different cubicles (in reality, all stimulus information was preprogrammed). Additionally, participants were informed that a lottery would be held and that a number of lottery tickets would be allocated to their group. The participants then conducted an additive group task: For 10 minutes, participants counted squares within figures on the screen. After typing in the correct number of squares, a new figure emerged on the screen. Participants had to complete as many figures 
as possible within the 10 minutes. All individual performances would be summed up into one general team performance. Following this group task, we induced the intragroup status manipulation: Participants were informed that with their individual performance they had contributed the most versus on average versus the least to the group performance and that they were therefore the highest versus on average versus the lowest in status in the group. Additionally, we induced a condition in which participants received no information about their intragroup status.

The manipulation of intragroup status was followed by a manipulation of voice as opposed to no-voice procedures: Through the computer network participants were versus were not allowed to voice their opinions about the percentage of lottery tickets that should be allocated to their group. Main dependent measures were participants' procedure judgements: Participants were asked questions on 7-point scales about the perceived fairness of and their satisfaction with the procedures used to divide the lottery tickets.

The results of this study are depicted in Figure 2 and showed significantly stronger procedural fairness effects in the high, average, and low intragroup status conditions than in the no-information condition. Thus, informing participants about their intragroup status, thereby making status a salient issue to participants, led to stronger reactions to voice as opposed to novoice procedures than not informing participants about status. Furthermore, the results showed no significant differences between the high, average, and low status conditions. In other words, procedural fairness effects were significantly influenced by the presence versus absence of status information, and not by intragroup status differences. These findings suggest that status salience constitutes a primary element in the relation between intragroup status and procedural justice, given that the mere presence of intragroup status information was sufficient to amplify procedural fairness effects.

\section{Inclusion and procedural justice}

Following our overview of studies on the effects of standing-as-status on procedural fairness effects, we now turn to the other interpretation of standing that was identified in the procedural justice literature: people's inclusion in a group (Cropanzano et al., 2001b; Lind, 2001; Lind \& Tyler, 1988; Tyler \& Blader, 2002). To complete our investigation of the relation between standing and procedural justice we have conducted research on the relation between people's sense of inclusion and procedural justice. In three experiments we have investigated the effects of inclusion on procedural fairness effects (Van Prooijen, Van den Bos, \& Wilke, in press). Based on the relational model, we argued that people's sense of inclusion has important 
Voice procedure

$\square$ No-voice procedure

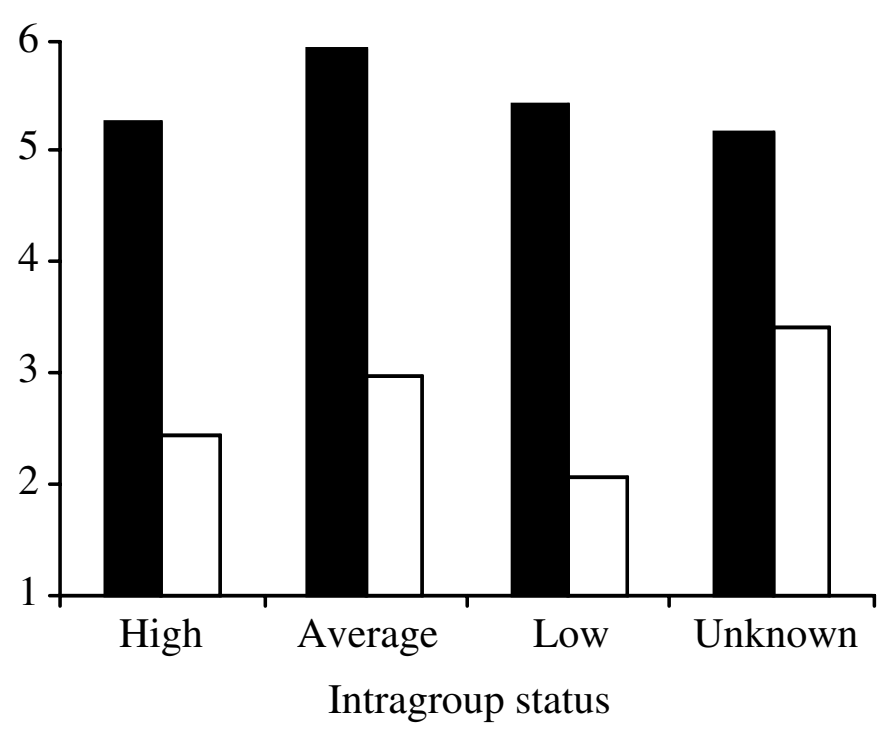

Figure 2. Mean procedure judgements as a function of intragroup status and procedure. Procedure judgements were measured on 7-point scales with higher means indicating more positive procedure judgements. Adapted from Van Prooijen et al. (2003).

consequences for subsequent procedural fairness effects. More specifically, inclusion in a group is associated with procedural justice because procedures convey symbolic messages of inclusion (Lind \& Tyler, 1988). The perceived fairness of the procedures adopted by group authorities may therefore affirm people's inclusion in social groups: Fair procedures can provide positive and stable intragroup relationships, but unfair procedures can lead groups or relationships to disintegrate (Lind, 2001; Tyler \& Lind, 1992).

Interesting in this respect are findings by Sleebos, Ellemers, and De Gilder (2003). These authors manipulated whether participants were versus were not included by fellow group members. The inclusion manipulation was followed by a lexical decision task: A series of letters appeared on the computer screen, and participants were asked to indicate as quickly and accurately as possible whether or not the letters formed an existing Dutch word or a nonword. The existing Dutch words were either fairness-related or non-fairness related words. The results indicated that, compared with the 
non-fairness related words, included participants responded faster to fairness-related words than excluded participants. In general, faster response latencies in lexical decision tasks are interpreted as increased levels of cognitive accessibility (cf. Bargh \& Chartrand, 2000). The results of this study thus showed that fairness is more cognitively accessible among included individuals than among excluded individuals.

In correspondence with the Sleebos et al. (2003) findings, Van Prooijen et al. (in press) hypothesised that people display procedural fairness effects of different strengths following experiences of inclusion versus following experiences of exclusion. Experiences of social inclusion are cognitively and behaviourally associated with procedural justice: After all, it has been argued that procedural justice conveys symbolic messages of inclusion and may thus affirm people's general sense of inclusion (Lind \& Tyler, 1988; Tyler \& Lind, 1992). From this, it can be inferred that procedural justice is more relevant to people when they are included than when they are excluded, because following an experience of inclusion there is a larger range of inclusionary feelings that can be affirmed than following an experience of exclusion. Following the argument that inclusion in a group is mentally associated with fairness (Sleebos et al., 2003), and contrary to what was assumed before, it is important to note here that in our line of reasoning the relation between inclusion and procedural justice has to do with a general sense of inclusion, instead of inclusion in a specific and identifiable group. We therefore tested the relation between inclusion and procedural justice in situations where the procedure was provided by an authority who was not a group member and the procedure had no direct relation with the participants' group membership (Van Prooijen et al., in press). Despite this lack of a direct connection between the inclusion/exclusion experience and the procedure, we predicted that following an experience of inclusion people are more sensitive to the fairness of procedures, and thus show stronger procedural fairness effects, than following an experience of exclusion.

To investigate this hypothesis, we conducted three experiments. For the current purposes we only discuss Experiments 2 and 3 (Experiment 1 was a scenario experiment showing the same results as Experiment 2). In Experiment 2, we directly manipulated whether or not participants were included versus excluded by their peers. To induce the manipulation of inclusion, participants conducted tasks in a laboratory group of eight persons. The tasks that participants conducted constituted the same additive group task as in the intragroup status experiment described previously (Van Prooijen et al., 2003). Following these tasks, participants in the current experiment were told that previous participating groups had consisted of seven persons. To make group task performances comparable, one person had to be excluded from the group. This excluded person would still finish the study, but he/she would no longer be a group member and his/her 
individual score on the tasks would not count for the team score. The decision to exclude one participant was taken in two steps. First, two members of the group were drawn by chance ("nominated for exclusion") and it was made clear that only one of these nominated group members would be excluded. Second, the remaining six members voted through the computer network for the participant who would be included and the participant who would be excluded.

In reality, the participant was always nominated for exclusion. Participants were either included by their peers (inclusion condition), excluded by their peers (exclusion condition), or the election was not yet held (not-yet-known condition). Participants were informed that all participants (both the included and the excluded) would conduct a second round of tasks. This round included the procedure manipulation: We again manipulated voice as opposed to no-voice procedures (Folger, 1977). To make sure that manipulations were orthogonal, participants received voice about something that was unrelated to their group membership (i.e., their individual number of tasks to be completed in an alleged second round of tasks) from an authority who was not a group member. Specifically, participants received a message through the computer network that they were versus were not allowed an opportunity to voice their opinion about their individual number of tasks that they had to complete in the second work round (cf. Lind et al., 1990). Dependent measures were procedural justice judgements and satisfaction ratings: Participants were asked questions referring to the perceived fairness of and their satisfaction with the procedure used to determine the number of tasks to be completed (Lind \& Tyler, 1988; Tyler \& Lind, 1992; Van den Bos \& Van Prooijen, 2001).

Manipulation check findings showed that participants indeed felt more included in the inclusion condition than in the exclusion condition. Furthermore, results showed that voice as opposed to no-voice procedures exerted stronger effects on both procedural justice judgements and satisfaction ratings following an experience of inclusion by peers than following an experience of exclusion by peers. The results regarding participants' procedural justice judgements are illustrated in Figure 3 (satisfaction ratings yielded similar results). These findings reveal that when participants were included by peers, procedural fairness effects were stronger than when participants were excluded by peers. These results suggest that people are more sensitive to procedures when they are included than when they are excluded, and corroborate the prediction that people's sense of inclusion causally influences procedural fairness effects.

The findings were extended in a third experiment (Van Prooijen et al., in press). This third experiment investigated whether people who generally feel included by peers in their lives would react more strongly to variations in procedural justice than people who do not feel included by peers in their 


\section{- Voice procedure}

$\square$ No-voice procedure

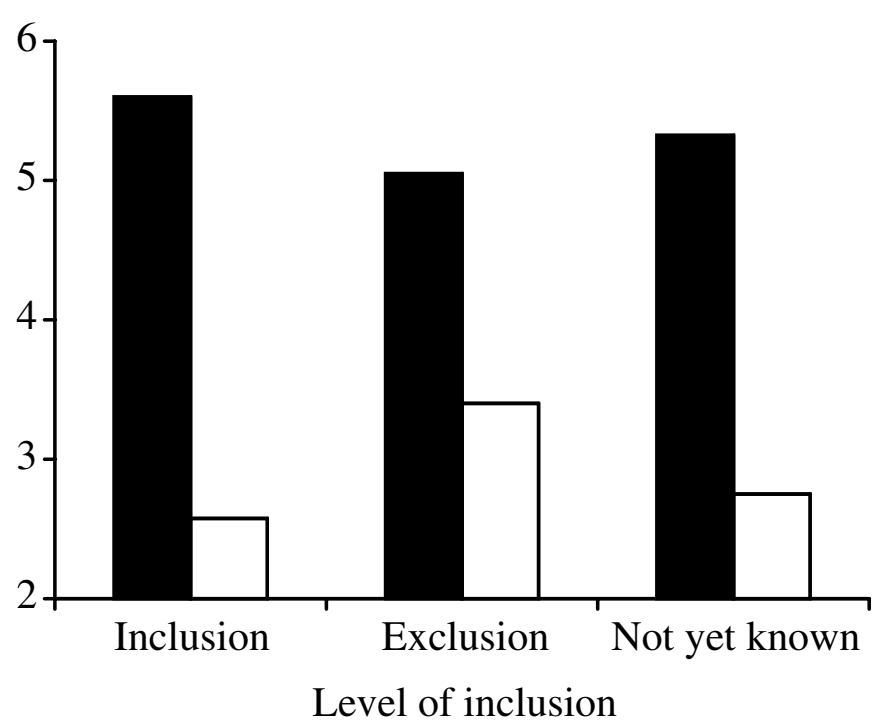

Figure 3. Mean procedural justice judgements as a function of level of inclusion and procedure. Procedural justice judgements were measured on 7-point scales with higher means indicating more positive procedural justice judgements. Adapted from Van Prooijen et al. (in press).

lives. This hypothesis is based on the argument that procedural justice affirms people's general sense of inclusion, instead of inclusion in one specific and identifiable group membership. As a consequence, procedural justice is a more accessible social norm for people who generally feel included by peers in their lives (Sleebos et al., 2003). We therefore predicted that procedural fairness effects would be stronger among those who reported experiencing a lot of inclusion in their lives than among those who reported not experiencing a lot of inclusion in their lives.

In the third experiment we first measured the extent to which participants felt included by peers in their lives with a 10-item scale. Examples of representative items are "I am typically someone who has a lot of friends", "There are only a few people that are really important to me", (recoded), "I have the feeling that a lot of people accept me" and "There are a lot of people that I can go to when I am in trouble". This Belongingness in life scale was inspired by the Need to belong scale (Leary, Kelly, Cottrell, \& 
Schreiendorfer, 2001), but was modified in the sense that we asked for participants' perceptions of their actual inclusion, instead of asking for the need to be included. Participants then were informed that the study had ended and that they would proceed with a second, unrelated study. In this "second study", participants were informed that they could win a prize in a lottery and that lottery tickets would therefore be divided among participants. Following previous studies (e.g., Van den Bos et al., 1998a; Van Prooijen et al., 2002) participants received a computer message from the experimenter stating that they were versus were not allowed an opportunity to voice their opinion about the number of lottery tickets that they thought they should receive. Participants in the voice condition subsequently typed in a number. In correspondence with the earlier-described experiment (Van Prooijen et al., in press, Experiment 2), dependent variables were procedural justice judgements and satisfaction ratings.

Hierarchical regression analyses showed that the differences between voice and no-voice procedures on procedural justice judgements and satisfaction ratings were stronger among those who experienced high levels of inclusion in their lives than among those who experienced low levels of inclusion in their lives. The results of the hierarchical regression analyses on procedural justice judgements are illustrated in Figure 4 (satisfaction ratings showed identical results). As predicted, high ratings of inclusion with peers were significantly associated with stronger procedural fairness effects than low ratings of inclusion with peers. These results further demonstrate that people's sense of inclusion moderates procedural fairness effects.

\section{IMPLICATIONS AND CONCLUSIONS}

In the current chapter we have reviewed empirical findings to address three limitations in scientists' understanding of the relation between standing and procedural justice: (1) In the literature there have been two interpretations of the standing construct (i.e., standing-as-status and standing-as-inclusion); (2) previous research has not demonstrated causality; and (3) it is as yet unclear why standing and procedural justice are related. In the following, we address the question of what the described empirical findings imply for these concerns.

First, it can be concluded that both intragroup status (Smith \& Tyler, 1997; Tyler, 1989, 1994; Tyler \& Blader, 2002) and inclusion (Lind, 2001; Lind \& Tyler, 1988; see also De Cremer, 2002) are related to procedural justice. Both status and inclusion are aspects of people's position in social groups that may shape people's reactions to procedures (Van Prooijen et al., 2002,2003 , in press). Additionally, it can be noted here that there are several similarities when comparing the relation between status and procedural justice with the relation between inclusion and procedural justice. That is, it 


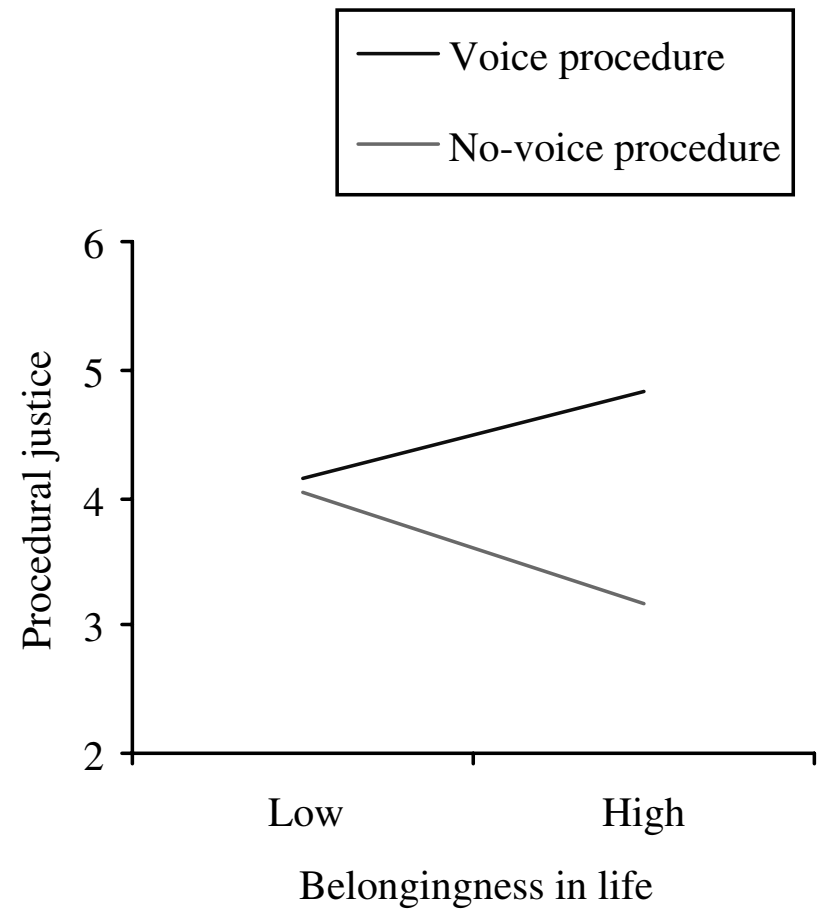

Figure 4. Mean procedural justice judgements as a function of belongingness in life and procedure. Procedural justice judgements were measured on 7-point scales with higher means indicating more positive procedural justice judgements. Adapted from Van Prooijen et al. (in press).

has been demonstrated that both status information (Van Prooijen et al., 2002) and inclusion information (Sleebos et al., 2003) can increase the extent to which fairness concerns are cognitively accessible. In correspondence with these findings, both status information (Van Prooijen et al., 2003) and inclusion information (Van Prooijen et al., in press) are able to enhance procedural fairness effects. This suggests that both the standing-as-status and the standing-as-inclusion operationalisations of the standing construct lead people to be more sensitive to variations in procedures.

That there is some convergence in the findings with status and inclusion may be attributable to the fact that, at least to some extent, status and inclusion are related conceptually. For example, perceptions of high status may cause feelings of inclusion, and perceptions of low status can lead to feelings of exclusion. Furthermore, both the status construct and the inclusion construct refer to how people perceive themselves in relation to 


\section{2}

VAN PROOIJEN ET AL.

social groups. However, this does not imply that status and inclusion essentially refer to the same underlying concept (Lind, 2001). After all, perceptions of inclusion or exclusion may not necessarily be caused by status differences; likewise, perceptions of status differences can have different consequences than inclusion or exclusion. Thus, although there are conceptual similarities between both standing operationalisations, there are also clear conceptual differences between someone's perceived status position in a group and people's perceptions of whether or not they belong to the group.

At the empirical level, it should be noted here that there are important differences between the effects of status and inclusion on procedural fairness effects. That is, the findings reviewed here suggest that the relation between status and procedural justice primarily depends on salience of the status construct. This is evident in the status salience studies, which showed that status salience amplified procedural fairness effects and, additionally, made fairness concerns more cognitively accessible (Van Prooijen et al., 2002). Furthermore, when intragroup status differences were introduced, procedural fairness effects were influenced by the absence versus presence of status information, and not by participants' status position (high vs average vs low). These findings do not mirror the inclusion findings: In the reported inclusion studies, included participants showed stronger procedural fairness effects than excluded participants (Van Prooijen et al., in press). Thus, whereas procedural fairness effects did not differentiate between various levels of relative intragroup status, procedural fairness effects did differentiate between included versus excluded individuals. This underscores that procedural justice researchers should be more specific in their reference to the standing construct, because the findings reviewed here suggest that the relationship between standing-as-status and procedural justice is psychologically different from the relationship between standing-as-inclusion and procedural justice.

A second conclusion that can be drawn from this chapter concerns the causality of the relation between standing and procedural fairness effects. Although the relational model has assumed a causal relation of standing influencing procedural fairness effects, previous empirical work on this topic has only reported correlational survey data (see, e.g., Smith \& Tyler, 1997; Tyler, 1989, 1994; Tyler \& Blader, 2002; Tyler et al., 1996). In the current chapter we have reported evidence that standing causally influences procedural fairness effects (Tyler \& Lind, 1992). This relation was found on both the status conceptualisation of standing and the inclusion conceptualisation of standing. Although this does not rule out the possibility that procedural justice affects perceptions of status or inclusion as well, the present chapter does support the causal order that is central in the relational model (Tyler \& Lind, 1992). 
A third aim of this chapter was to understand the underlying processes that explain why standing and procedural justice are related. In the following we attempt to do so by trying to theoretically integrate the propositions of the current chapter.

\section{Towards theoretical integration}

In the current chapter we have scrutinised social standing as antecedent of procedural fairness effects. Although we have noted that the two described conceptualisations of standing (i.e., standing-as-status and standing-asinclusion) differ both conceptually and empirically, we have also noted that there is at the same time some conceptual convergence between the status and inclusion conceptualisations. This convergence is reflected empirically by the finding that both standing-as-status and standing-as-inclusion cognitively activate fairness considerations (Sleebos et al., 2003; Van Prooijen et al., 2002). These latter findings suggest that the relation between standing and procedural justice is more deeply rooted in people's minds than has been recognised before. To understand the role of standing in the psychology of procedural justice we argue that we have to concentrate on the convergence rather than on the divergence of the status and inclusion constructs. Indeed, the fact that status and inclusion share some conceptual common ground may have been reason why researchers have interpreted the standing construct differently.

Building on the relational model (Tyler \& Lind, 1992), we start out with the premise that standing is associated with the extent to which people think that they are held in regard by others. This is the case for both intragroup status and inclusion. To illustrate, people can think that they are held in high or low regard because of their intragroup status. For example, if people perform well, they conclude that they have high intragroup status and are held in high regard by fellow group members, but if they perform poorly, they may believe that they have low intragroup status and are held in low regard (Tyler \& Blader, 2002). Likewise, people can think that they are held in high regard because they are included in a group, but people can believe that they are held in low regard because they are excluded from a group. Thus, information that is related to people's position in a group is mentally associated with the regard and approval that people receive from others. As a consequence, standing-related information leads people to be more sensitive to procedural justice, because procedural justice is also associated with the extent to which people are held in regard by others. After all, the relational model has posited that people use procedural justice information to make inferences about standing-related information such as how people are held in regard by others (Tyler et al., 1996; Tyler \& Lind, 1992). Information about 


\section{4}

VAN PROOIJEN ET AL.

standing thus leads people to mentally associate their position in social groups with procedural justice.

More generally, we propose here that when people encounter social stimuli that are related to their positions in social groups, people's fairness concerns become more accessible (Sleebos et al., 2003; Van Prooijen et al., 2002). As a consequence, focusing people on issues of status or inclusion cognitively activates their fairness concerns. An implication of this is that focusing people on standing-related information stimulates them to start thinking about procedural justice issues. This increases attentiveness to variations in procedural justice when people come across information about their position in social groups that leads them to display stronger procedural fairness effects.

The line of reasoning laid out here extends the relational model because it puts emphasis on the process of how standing information influences procedural fairness effects. Additionally, it can be noted here that some of the above propositions show a resemblance to recent arguments put forward by Skitka (2003). These authors adopted an "accessible identity approach" to understand the conditions under which people start thinking about fairness. More specifically, Skitka distinguished between three identity components: people's material identity, people's social identity, and people's personal or moral identity. Material identity consists of one's material extensions of the self (e.g., personal belongings). Social identity consists of interpersonal and relational extensions of the self (e.g., group memberships). Personal (or moral) identity refers to one's internalised values and norms (e.g., attitudes towards freedoms of speech). Skitka argued that priming aspects of these three different identities activates corresponding fairness considerations. For example, in situations where people's material identity is salient, distributive justice concerns become cognitive activated and people start thinking about distributive justice issues. These arguments correspond to the proposition of the current chapter that social information may affect the extent to which people's procedural justice considerations are accessible.

\section{Closing comments}

The argument that people's position in groups may activate fairness concerns points at a worthwhile direction for future justice researchers to pursue. Justice researchers may want to start using social cognition methodologies to investigate what kinds of standing-related information activate fairness concerns. Recent studies have developed measures to ascertain the extent to which fairness concerns are cognitively accessible, either by means of word-fragment completions (Van Prooijen et al., 2002) or by assessing response latencies (Sleebos et al., 2003; see also Van den Bos \& Van Prooijen, 2001). Applying social cognition methodologies to under- 
stand procedural justice issues may be a worthwhile endeavour to pursue in future justice research, because this may deepen scientists' understanding of the conditions under which people start thinking about fairness (Skitka, 2003).

More generally, we would like to make a plea here for more precise exploration of the psychological processes underlying procedural justice issues. Many researchers have proposed that it is important to understand the psychological processes underlying procedural fairness effects (Cropanzano et al., 2001a; Folger \& Cropanzano, 1998; Lind \& Tyler, 1988; Tyler \& Lind, 1992; Van den Bos, Lind, \& Wilke, 2001). However, we argue here that to really understand the psychological processes underlying procedural fairness effects scientists have to collect cognitive process data. Yet, only recently have a few justice researchers attempted to collect such process data (Hafer, 2000; Miedema, Van den Bos, \& Vermunt, 2000; Sleebos et al., 2003; Steiner, Guirard, \& Baccino, 1999; Van den Bos \& Van Prooijen, 2001; Van Prooijen et al., 2002). We would like to emphasise here that such data are the key to really understanding the processes that explain how and when people form judgements of fairness or unfairness. The lack of cognitive process data constitutes a serious missing link in empirical procedural justice research.

To return to the concepts that motivated the current contribution, in this chapter we have provided an overview of the standing construct in procedural justice. We have tried to increase conceptual clarity by making explicit that researchers have defined standing differently in their workthat is, either as intragroup status or as matters of inclusion. Furthermore, we have tried to increase empirical clarity by reviewing evidence showing that both standing-as-status and standing-as-inclusion causally affect procedural fairness effects. Finally, we have tried to theoretically integrate the propositions of the current chapter by explaining how the standing construct may influence procedural fairness effects. It can be concluded that the standing construct plays an important role in the psychology of procedural justice.

\section{REFERENCES}

Adams, J. S. (1965). Inequity in social exchange. In L. Berkowitz (Ed.), Advances in experimental social psychology (Vol. 2, pp. 267-299). New York: Academic Press.

Ambrose, M. L., \& Kulik, C. T. (2001). How do I know that's fair? A categorization approach to fairness judgements. In S. W. Gilliland, D. D. Steiner, \& D. P. Skarlicki (Eds.), Research in social issues in management (Vol. 1, pp. 35-62). Greenwich, CT: Information Age Publishing.

Bargh, J. A., \& Chartrand, T. L. (2000). The mind in the middle: A practical guide to priming and automaticity research. In H. T. Reis \& C. M. Judd (Eds.), Handbook of research methods in social and personality psychology (pp. 253-285). New York: Cambridge University Press. 


\section{6}

VAN PROOIJEN ET AL.

Baumeister, R. F., \& Leary, M. R. (1995). The need to belong: Desire for interpersonal attachments as a fundamental human motive. Psychological Bulletin, 117, 497-529.

Brewer, M. B. (1991). The social self: On being the same and different at the same time. Personality and Social Psychology Bulletin, 17, 475-482.

Brockner, J., Heuer, L., Siegel, P. A., Wiesenfeld, B., Martin, C., Grover, S., et al. (1998). The moderating effect of self-esteem in reaction to voice: Converging evidence from five studies. Journal of Personality and Social Psychology, 75, 394-407.

Brockner, J., \& Wiesenfeld, B. M. (1996). An integrative framework for explaining reactions to decisions: Interactive effects of outcomes and procedures. Psychological Bulletin, 120, 189208.

Chen, S., Lee-Chai, A. Y., \& Bargh, J. A. (2001). Relationship orientation as a moderator of the effects of social power. Journal of Personality and Social Psychology, 80, 173-187.

Chen, Y.-R., Brockner, J., \& Greenberg, J. (2003). When is it "a pleasure to do business with you"? The effects of relative status, outcome favorability, and procedural fairness. Organizational Behaviour and Human Decision Processes, 92, 1-21.

Cropanzano, R., Byrne, Z. S., Bobocel, D. R., \& Rupp, D. E. (2001a). Moral virtues, fairness heuristics, social entities, and other denizens of organizational justice. Journal of Vocational Behaviour, 58, 164-209.

Cropanzano, R., Rupp, D. E., Mohler, C. J., \& Schminke, M. (2001b). Three roads to organizational justice. In J. Ferris (Ed.), Review of personnel and human resources management (Vol. 20, pp. 1-113). Greenwich, CT: JAI Press.

De Cremer, D. (2002). Respect and cooperation in social dilemmas: The importance of feeling included. Personality and Social Psychology Bulletin, 28, 1335-1341.

Feather, N. (1994). Attitudes toward high achievers and reactions to their fall: Theory and research concerning tall poppies. In M. P. Zanna (Ed.), Advances in experimental social psychology (Vol. 26, pp. 1-73). San Diego, CA: Academic Press.

Folger, R. (1977). Distributive and procedural justice: Combined impact of "voice" and improvement on experienced inequity. Journal of Personality and Social Psychology, 35, $108-119$.

Folger, R. (1984). Emerging issues in the social psychology of justice. In R. Folger (Ed.), The sense of injustice: Social psychological perspectives (pp. 3-24). New York: Plenum.

Folger, R., \& Cropanzano, R. (1998). Organizational justice and human resource management. Thousand Oaks, CA: Sage.

Folger, R., Rosenfield, D., Grove, J., \& Corkran, L. (1979). Effects of "voice" and peer opinions on responses to inequity. Journal of Personality and Social Psychology, 37, 2253 2261.

Greenberg, J., \& Folger, R. (1983). Procedural justice, participation, and the fair process effect in groups and organizations. In P. B. Paulus (Ed.), Basic group processes (pp. 235-256). New York: Springer-Verlag.

Hafer, C. L. (2000). Do innocent victims threaten the belief in a just world? Evidence from a modified Stroop task. Journal of Personality and Social Psychology, 79, 165-173.

Leary, M. R., Kelly, K. M., Cottrell, C. A., \& Schreiendorfer, L. S. (2001). Individual differences in the need to belong. Unpublished manuscript.

Lind, E. A. (2001). Thinking critically about justice judgements. Journal of Vocational Behaviour, 58, 220-226.

Lind, E. A., Kanfer, R., \& Earley, P. C. (1990). Voice, control, and procedural justice: Instrumental and noninstrumental concerns in fairness judgements. Journal of Personality and Social Psychology, 59, 952-959.

Lind, E. A., \& Tyler, T. R. (1988). The social psychology of procedural justice. New York: Plenum. 
Miedema, J., Van den Bos, K., \& Vermunt, R. (2000). Rechtvaardigheid, onrechtvaardigheid, en tapas [Justice, injustice, and tapas]. Paper presented at the Fourteenth ASPO conference, Nijmegen, the Netherlands.

Skitka, L. J. (2003). Of different minds: An accessible identity model of justice reasoning. Personality and Social Psychology Review, 7, 286-297.

Sleebos, E., Ellemers, N., \& De Gilder, D. (2003). The carrot and the stick. Respect and group serving effort: Collective and individual motives to exert effort in task-groups. Paper presented at the Round Table of Organizational Justice, Utrecht, the Netherlands.

Smith, H. J., \& Tyler, T. R. (1997). Choosing the right pond: The impact of group membership on self-esteem and group-oriented behaviour. Journal of Experimental Social Psychology, 33, $146-170$.

Smith, H. J., Tyler, T. R., Huo, Y. J., Ortiz, D. J., \& Lind, E. A. (1998). The self-relevant implications of the group-value model: Group membership, self-worth, and treatment quality. Journal of Experimental Social Psychology, 34, 470-493.

Ståhl, T., Van Prooijen, J.-W., \& Vermunt, R. (in press). On the psychology of procedural justice: Reactions to procedures of ingroup vs. outgroup authorities. European Journal of Social Psychology.

Steiner, D. D., Guirard, S., \& Baccino, T. (1999, May). Cognitive processing of procedural justice information: Application of the oculometer. Paper presented at the annual conference of the Society for Industrial/Organziational Psychology, Atlanta.

Tajfel, H., \& Turner, J. C. (1979). An integrative theory of intergroup conflict. In W. G. Austin \& S. Worchel (Eds.), The social psychology of intergroup relations (pp. 33-47). Monterey, CA: Brooks/Cole.

Thibaut, J., \& Walker, L. (1975). Procedural justice: A psychological analysis. Hillsdale, NJ: Lawrence Erlbaum Associates Inc.

Turner, J. C., Hogg, M. A., Oakes, P. J., Reicher, S. D., \& Wetherell, M. S. (1987). Rediscovering the social group: A self-categorization theory. Oxford: Basil Blackwell.

Tyler, T. R. (1987). Conditions leading to value expressive effects in judgments of procedural justice: A test of form models. Journal of Personality and Social Psychology, 52, 333-344.

Tyler, T. R. (1989). The psychology of procedural justice: A test of the groupvalue model. Journal of Personality and Social Psychology, 57, 830-838.

Tyler, T. R. (1994). Psychological models of the justice motive: Antecedents of distributive and procedural justice. Journal of Personality and Social Psychology, 5, 850-863.

Tyler, T. R., \& Blader, S. L. (2000). Cooperation in groups: Procedural justice, social identity, and behavioral engagement. Hove. UK: Psychology Press.

Tyler, T. R., \& Blader, S. L. (2002). Autonomous vs. comparative status: Must we be better than others to feel good about ourselves? Organizational Behavior and Human Decision Processes, 89, 813-838.

Tyler, T. R., Degoey, P., \& Smith, H. (1996). Understanding why the justice of group procedures matters: A test of the psychological dynamics of the group-value model. Journal of Personality and Social Psychology, 70, 913-930.

Tyler, T. R., \& Lind, E. A. (1992). A relational model of authority in groups. In M. Zanna (Ed.), Advances in experimental social psychology (Vol. 25, pp. 115-292). San Diego, CA: Academic Press.

Van den Bos, K. (1999). What are we talking about when we talk about novoice procedures? On the psychology of the fair outcome effect. Journal of Experimental Social Psychology, 35, $560-577$.

Van den Bos, K. (2001). Uncertainty management: The influence of human uncertainty on reactions to perceived fairness. Journal of Personality and Social Psychology, 80, 931-941. 


\section{VAN PROOIJEN ET AL.}

Van den Bos, K., Bruins, J., Wilke, H. A. M., \& Dronkert, E. (1999). Sometimes unfair procedures have nice aspects: On the psychology of the fair process effect. Journal of Personality and Social Psychology, 77, 324-336.

Van den Bos, K., \& Lind, E. A. (2002). Uncertainty management by means of fairness judgements. In M. P. Zanna (Ed.), Advances in experimental social psychology (Vol. 34, pp. 1-60). San Diego, CA: Academic Press.

Van den Bos, K., Lind, E. A., Vermunt, R., \& Wilke, H. A. M. (1997a). How do I judge my outcome when I do not know the outcome of others? The psychology of the fair process effect. Journal of Personality and Social Psychology, 72, 1034-1046.

Van den Bos, K., Lind, E. A., \& Wilke, H. A. M. (2001). The psychology of procedural and distributive justice viewed from the perspective of fairness heuristic theory. In R. Cropanzano (Ed.), Justice in the workplace: Volume 2: From theory to practice (pp. $49-$ 66). Mahwah, NJ: Lawrence Erlbaum Associates Inc.

Van den Bos, K., \& Miedema, J. (2000). Towards understanding why fairness matters: The influence of mortality salience on reactions to procedural fairness. Journal of Personality and Social Psychology, 79, 355-366.

Van den Bos, K., \& Van Prooijen, J.-W. (2001). Referent cognitions theory: The psychology of voice depends on closeness of reference points. Journal of Personality and Social Psychology, $81,616-626$.

Van den Bos, K., Vermunt, R., \& Wilke, H. A. M. (1997b). Procedural and distributive justice: What is fair depends more on what comes first than on what comes next. Journal of Personality and Social Psychology, 72, 95-104.

Van den Bos, K., Wilke, H. A. M., \& Lind, E. A. (1998a). When do we need procedural fairness? The role of trust in authority. Journal of Personality and Social Psychology, 75, $1449-1458$.

Van den Bos, K., Wilke, H. A. M., Lind, E. A., \& Vermunt, R. (1998b). Evaluating outcomes by means of the fair process effect: Evidence for different processes in fairness and satisfaction judgements. Journal of Personality and Social Psychology, 74, 1493-1503.

Van Prooijen, J.-W., Van den Bos, K., \& Wilke, H. A. M. (2002). Procedural justice and status: Status salience as antecedent of procedural fairness effects. Journal of Personality and Social Psychology, 83, 1353-1361.

Van Prooijen, J.-W., Van den Bos, K., \& Wilke, H. A. M. (2003). Knowing where we stand in a group enhances reactions to procedural justice: On the psychology of procedural justice and intragroup status. Manuscript submitted for publication.

Van Prooijen, J.-W., Van den Bos, K., \& Wilke, H. A. M. (in press). Group belongingness and procedural justice: Social inclusion and exclusion by peers affects the psychology of voice. Journal of Personality and Social Psychology. 